\title{
Development of a new joining technology for hybrid joints of sheet metal and continuous fiber-reinforced thermoplastics
}

\author{
Dimitri Krassmann ${ }^{1} \cdot$ Elmar Moritzer $^{1}$
}

Received: 4 November 2020 / Accepted: 23 September 2021 / Published online: 9 October 2021

(c) The Author(s) 2021, corrected publication 2022

\begin{abstract}
Punctiform mechanical joining technologies, such as riveting, clinching, or screwing, which are widely used in sheet metal processing, are frequently applied because they have been established for many years. Depending on the process, they offer a variety of advantages such as one-sided accessibility, re-detachability, and no need for pre-punching operations or auxiliary joining elements. In addition, the processes often guarantee a high process reliability and extensive process monitoring. However, with thermoplastic composites, they lead to considerable stress concentrations at the joint due to the fibers. Undesirable fiber and inter-fiber breaks then result. With the development of the novel joining technology of joint stamp riveting, an improvement is achieved in this situation that has been described for hybrid joints on components made of thermoplastic composites and metal sheets. The joining principle is based on the formation of a form lock between the joining partners. The thermoplastic composite is thermomechanically formed by means of a joint stamp without using an auxiliary joining element. Within the scope of a research project, the joining process was characterized with regard to the structure of the joining spot, the geometry of the forming tools, and also the mechanical properties for purposes of analyzing and designing the joining process.
\end{abstract}

Keywords Joint stamp riveting · Thermoplastic composites $\cdot$ Hybrid joining $\cdot$ Multi-material design $\cdot$ Thermoforming · Plastics

\section{Introduction}

The implementation of new construction methods and materials in vehicle and aircraft manufacturing is linked to the supply of reliable and more cost-effective joining technologies. The requisite mechanical properties of the joints must be ensured over the entire life cycle. The design of interfaces is also linked to the feasibility of being able to consider lightweight structures in designs at all. Consequently, the idea of lightweight construction with moving masses has

Recommended for publication by Commission XVI - Polymer Joining and Adhesive Technology

Dimitri Krassmann

dimitri.krassmann@ktp.upb.de

Elmar Moritzer

elmar.moritzer@ktp.upb.de

1 Kunststofftechnik Paderborn (KTP), Paderborn University, Warburger Straße 100, 33098 Paderborn, Germany a decisive influence on the choice of joining technologies used [1].

As current developments in the automotive industry show, the mix of materials used in the manufacture of vehicles has long been state of the art. For example, in the current fifth generation of the Audi A8 model [2], a mix of four materials is used in the body. This mix requires joining techniques that are appropriate to the materials and adapted to the respective requirements of the materials and the manufacturing and product-related conditions. Accordingly, a total of 13 different joining techniques are used to construct the body of the A8. Consequently, some of these joining technologies must be adapted to fiber-reinforced plastic material which is one of the materials employed.

Established joining technologies taken from metal sheet processing lead to a reduction in the load-bearing capacity of thermoplastic composites due to the interrupted force flow and the defects induced by cutting and squeezing processes. In the case of hybrid joints of composites and metal sheets, in particular, the composite material is usually the failure-relevant structure in the joint. In order to make the 
best possible use of the high lightweight construction potential of thermoplastic composites by comparison to metallic construction materials, it is, therefore, necessary to provide a joining technique that is adapted to the fiber-reinforced plastic composite (FRP). Conventional force-, form-, and material-locking joining systems require auxiliary joining elements that increase the component mass and make the joining process more complex. This also includes the drilling of holes for selective bolt and rivet connections. The mechanical drilling and punching of fasteners with a cutting component, in particular, causes undesirable fiber and interfiber breaks at the joint of the FRP. This means that the high material potential of the thermoplastic composite is only marginally exploited [3].

The development of the novel joining technology of joint stamp riveting for hybrid joints of thermoplastic composites and sheet metal counteracts the behavior described above. Possible applications for joint stamp riveting include the joining of structural fiber-plastic composite components to metal sheets or other joining partners in the automotive industry (examples: front end carrier, window lifter running rail, seat structures, rear seat through loading, etc.).

With this joining technology, the hybrid joint between the thermoplastic composite and the sheet metal is realized without any additional elements such as a rivet or a screw, thus, saving the complex process step of feeding the parts to be joined. The joining principle is based on the thermoforming of the thermoplastic composite to create a form closure between the two joining partners. It is not necessary to form the metallic joining partner. The joining process, thus, only requires a low-energy input.

The joining operation is performed by the joint stamp on one side, but a die is required on the rear side for forming. Both thin $(1 \mathrm{~mm})$ and thick thermoplastic composites $(3 \mathrm{~mm})$ can be joined. If necessary, a favorable choice of geometry can be used to ensure the tightness of the joint after the joining process, since the penetration of the fiberplastic composite does not lead to a through-hole. The forces that develop are transmitted through the fiber and matrix material in the joint area into the metal part, so that any high stress concentrations should be on a low level. The position of the fibers is advantageous here. They are not butt joined in front of a rivet element but are adapted through the hole of the metal joining partner.

\section{State of the art}

\subsection{Thermoplastic composites}

Continuous fiber-reinforced thermoplastics belong to the group of high-performance materials. They are plate-shaped, semi-finished products made of fabric with a thermoplastic matrix. The decisive feature of this fiber composite material is its thermoplastic matrix, since this makes the composite material thermally moldable. The fabrics used lead to anisotropy due to the fiber orientation. To achieve the best possible mechanical properties in one direction, the fibers should be as long as possible and oriented parallel to the direction of the force flow $[4,5]$.

In principle, thermoplastic composites can be constructed in several layers (Fig. 1). For some applications, however, thermoplastic composites with a single fabric layer are also sufficient [6]. This material is fully impregnated and consolidated. After production in a special pressing process, the material can be further processed as a function of the component. In this case, impregnating the fibers is more difficult than with thermosets. By contrast to thermosets, thermoplastics do not have a low viscosity in this process but are melt like with a significantly higher viscosity. For this reason, the manufacturing processes used for the production of semi-finished products differ from those used with thermosets $[7,8]$.

\subsection{Thermoforming of thermoplastic composites (TPC)}

Thermoforming is defined as the forming of a thermoplastic semi-finished product into a three-dimensional structure using pressure and temperature [9]. The semi-finished product must first be heated to the necessary forming temperature. The material is then positioned and formed in the tool. At this point, an accompanying holding system is required, which must not stretch the semi-finished product but allow it to be drawn in. After cooling, the three-dimensional structure can be removed and assembled (Fig. 2) [10-12].

The decisive process in the thermoforming of fabricreinforced thermoplastics is the draping of the pure fabric or the forming of the impregnated fabric, since unlike the thermoforming of pure thermoplastics, the forming cannot be achieved by a material flow [13]. This draping process

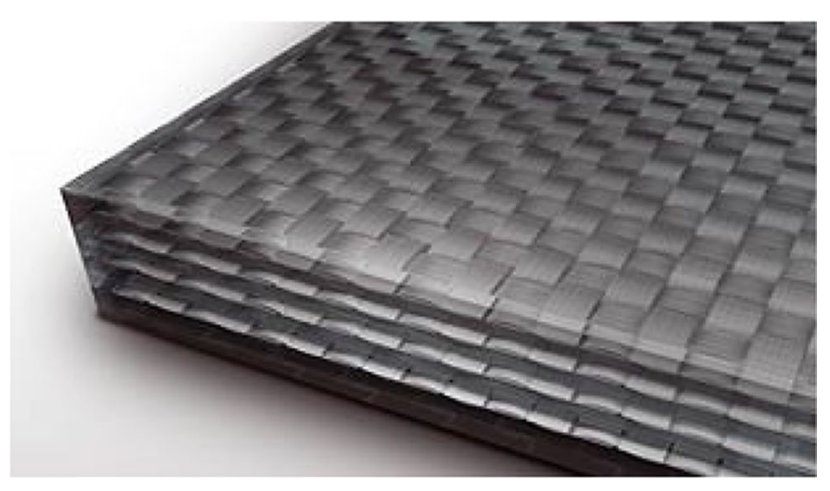

Fig. 1 Multilayer thermoplastic composite according to [37] 
Fig. 2 Process sequence for the thermoforming of thermoplastic composites according to [12]

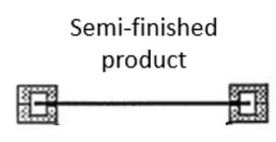

Inserting

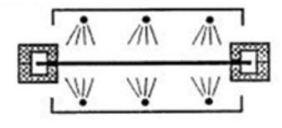

Heating

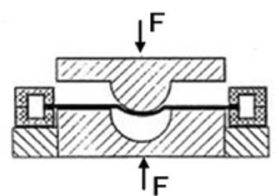

Forming + Cooling

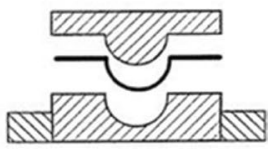

Removing
Fig. 3 Macroscopic forming processes of fabric-reinforced thermoplastics according to [13]

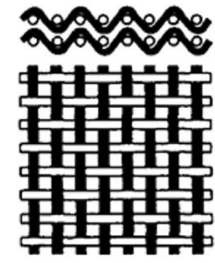

undeformed fabric
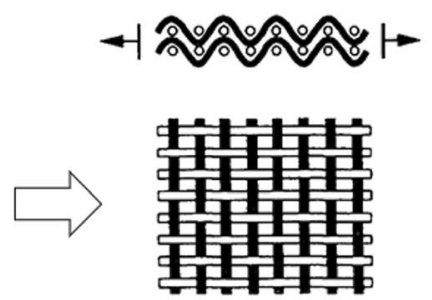

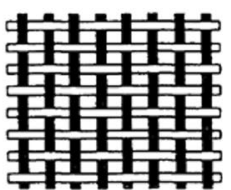

fabric stretching

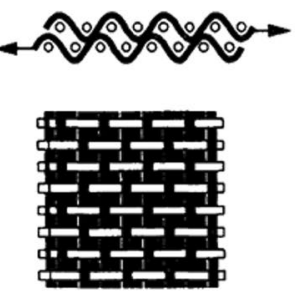

interlaminar sliding

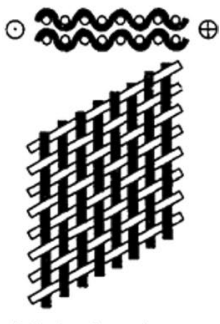

fabric shearing depends on the three basic macroscopic mechanisms of fabric stretching, interlaminar sliding, and fabric shearing. These mechanisms are shown schematically in Fig. 3. Fabric stretching does not refer to the elongation of individual filaments. Instead, it is a reduction in the waviness of the fabric under tensile load that leads to the stretching of the entire composite. The interlaminar sliding describes a relative movement of the individual fabric layers to each other. For two-dimensional forming processes, interlaminar sliding is the most important deformation mechanism. Fabric shearing, the characteristic mechanism for three-dimensional deformation, describes the opposite rotation of warp and weft threads, as set out in $[9,13,14]$.

In addition to macroscopic forming mechanisms, microscopic forming processes can also take place which influence the formability. The individual fiber rovings can be deformed by external forces, for example. This can lead to measurable local changes in the component thickness and the surface topography [9]. This effect is used to increase the mechanical properties of joint stamp riveting.

\subsection{Joining to hybrid components}

Joining technology is becoming increasingly important in the manufacture of lightweight structures, especially for automotive and aircraft construction. Low-heat joining processes, such as mechanical joining techniques and adhesive bonding plus combinations of the two, are increasingly becoming the focus of industry on account of the increased use being made of difficult-to-weld materials such as continuous-fiber-reinforced plastics and mixed designs with different materials $[15,16]$.

Common mechanical processes such as punch riveting are particularly unfavorable for joining fiber-plastic composites [17]. The continuous fibers of the thermoplastic composite are damaged during the joining process, resulting in stress concentrations under load due to the interrupted force flow and reducing the mechanical properties of the joint. Nevertheless, investigations were conducted into the behavior of hybrid joints on thermoplastic composites and metal sheets joined by different riveting methods using auxiliary joining elements such as self-pierce riveting [18] or blind riveting [19].

Different investigations have now been conducted into modified processes for joining metal and plastic. For

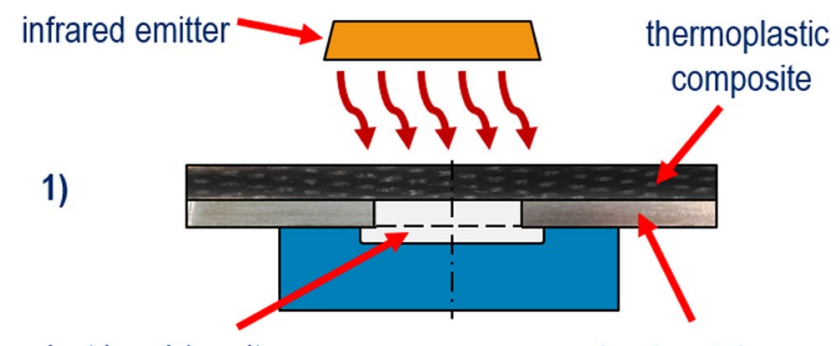

rivet head / cavity

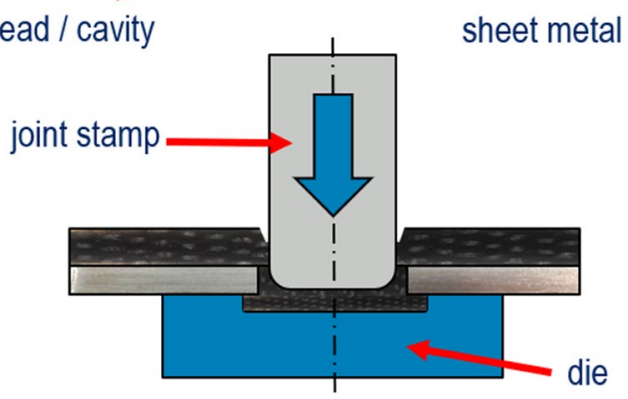

3)

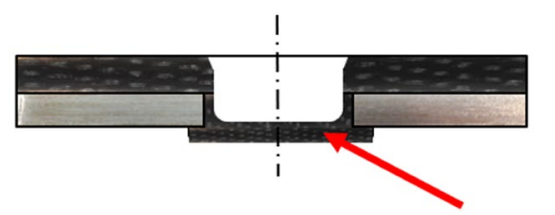

formed rivet head

Fig. 4 Process sequences of Joint Stamp Riveting 
Fig. 5 Rivet head and joint area of a joined sample
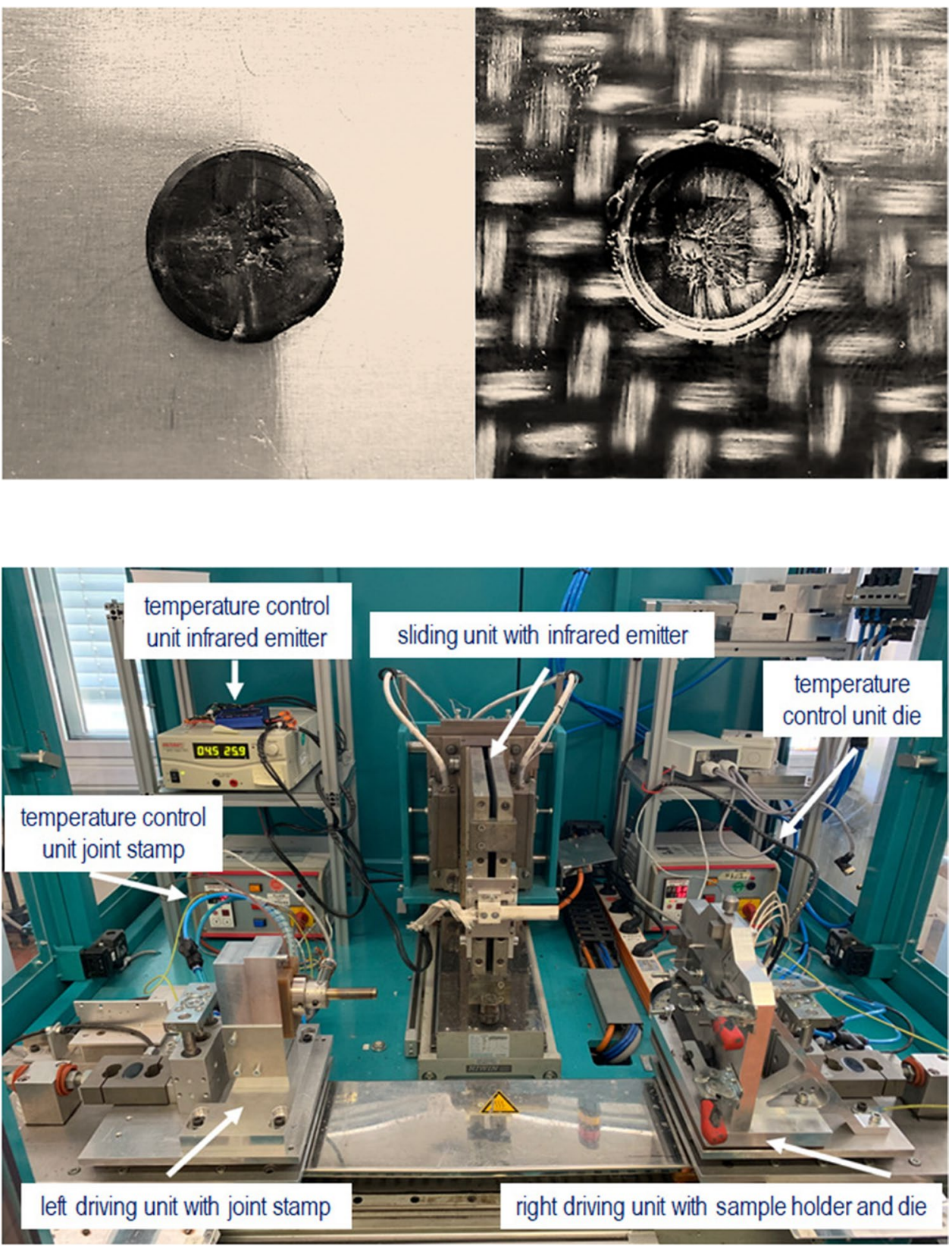

Fig. 6 Laboratory plant for Joint Stamp Riveting example, a process has been investigated, which leads to direct adhesion between the plastic and the metal in an injection molding process. This, however, requires extensive pretreatment and the use of a bonding agent. The studies also cover plastics that are not reinforced with continuous fibers [20-22].

Combinations of mechanical and adhesive joining methods are also currently being investigated [23-25]. The aim was to minimize the stress concentration caused by the mechanical joining process by means of planar force transmission through the adhesive layer.

A modified hot riveting process [26] was also considered, in which the metallic joining partner has an interlock that is filled with plastic material during the joining process so as to improve the pull-out properties of the joint, in particular. This study also covers plastics without fiber reinforcement.

In addition, new processes are being developed that adapt to the material behavior of thermoplastic fiber-plastic composites. In [27], the joining partners are formed with a rotating mandrel. The metallic joining partner forms a sleeve that penetrates the FRP. This makes allowance for the forming behavior of the FRP. The metallic joining partner is also formed, however. The process requires a relatively highenergy input. In addition, not all metal materials are equally suitable for this due to their forming behavior. 
A similar process was investigated in [28]. Here, the modified blind rivet serves as a forming tool, so it is not necessary to conduct forming on both sides. The metallic joining partner is also formed. The joining element will partially damage the fibers of the thermoplastic FRP during joining. The same applies to the screwing process according to [29]. The self-forming screw leads to partial fiber damage during penetration of the FRP.

A different approach is followed in [30]. In this research, a thermoplastic composite is formed with a mandrel via a pilot hole made in the metallic joining partner and is compressed into a collar on the rear side. This creates a throughhole and the FRP is formed from both sides. The forming process is designed in such a way that the composite does not show any fiber damage. The process is a combination of thermoforming and clinching with a fixed composite thickness of $4 \mathrm{~mm}$.

Research is also currently being conducted into twodimensional procedures such as press joining with and without prestructuring $[31,32]$. Methods using a laser beam for the joining process were a particular focus in $[33,34]$. While emphasis is placed on the joint with the FRP matrix in the case of press joining or adhesive bonding, it is the materialrelated properties of thermoplastic composites that are used for joining with micropin structures, because the pins pass through the fiber fabric and interlock into it $[31,35]$.

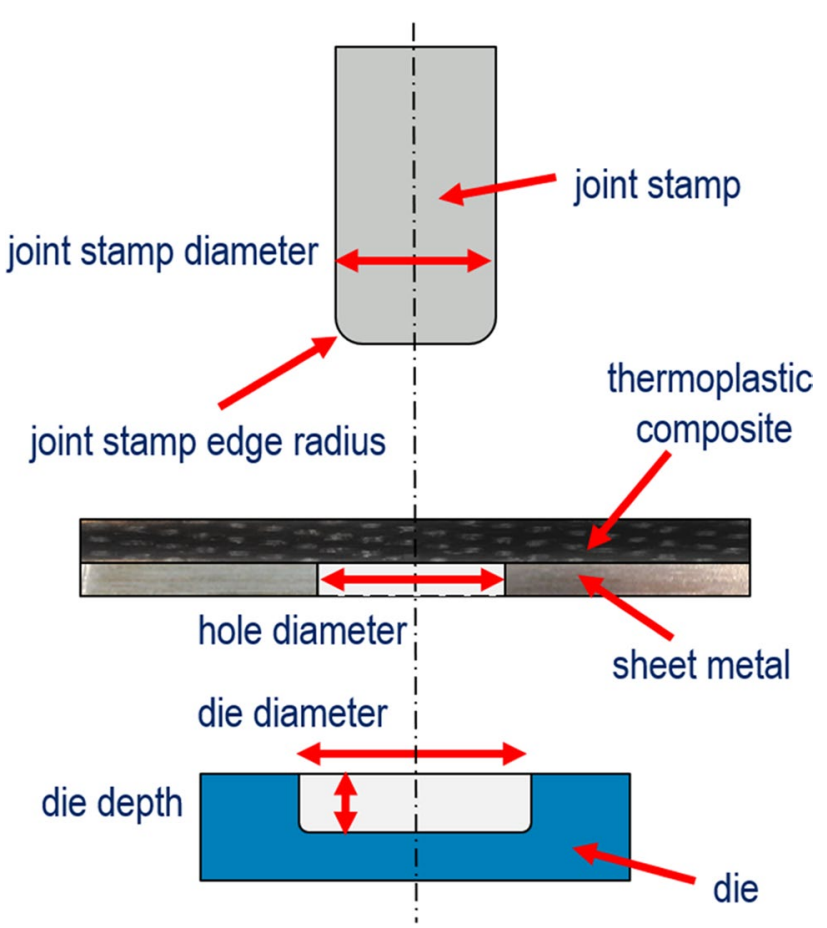

Fig. 7 Characteristic geometric parameters
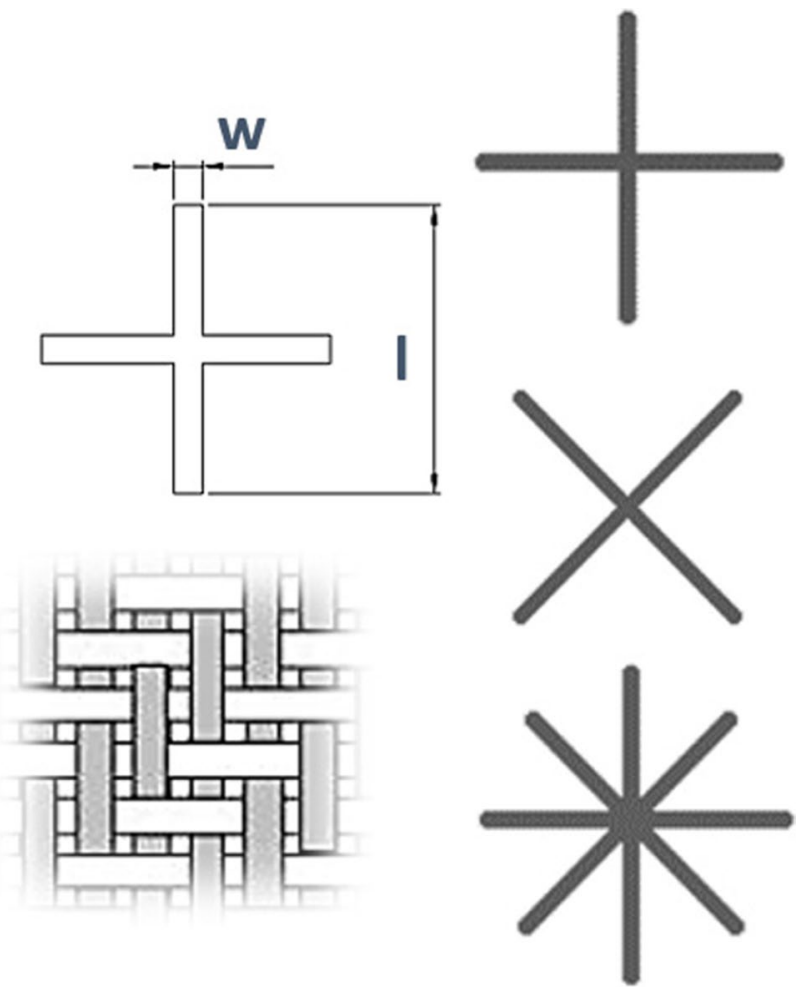

Fig. 8 Characteristic cutting parameters

\section{Experimental setup}

With the new joining technology of joint stamp riveting, the hybrid connection is produced in a similar way to $[27,30]$ without any additional element such as a rivet or a screw. The thermoforming approach according to [10] is used to ensure that a connection is achieved between the thermoplastic composite and the metal sheet.

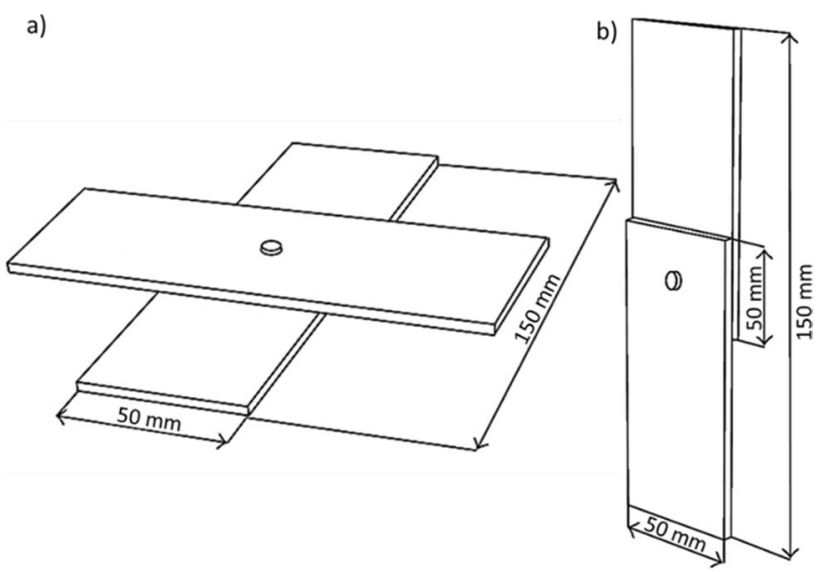

Fig. 9 Samples for cross-tension test (a) and tensile shear test (b) 


\begin{tabular}{|c|}
\hline $\begin{array}{c}\text { Joining Technology } \\
\text { Joint Stamp Riveting }\end{array}$ \\
\hline Materials \\
Tepex dynalite 104RG-600 $(2 \mathrm{~mm})$ \\
EN AW-5754 $(1.5 \mathrm{~mm})$
\end{tabular}

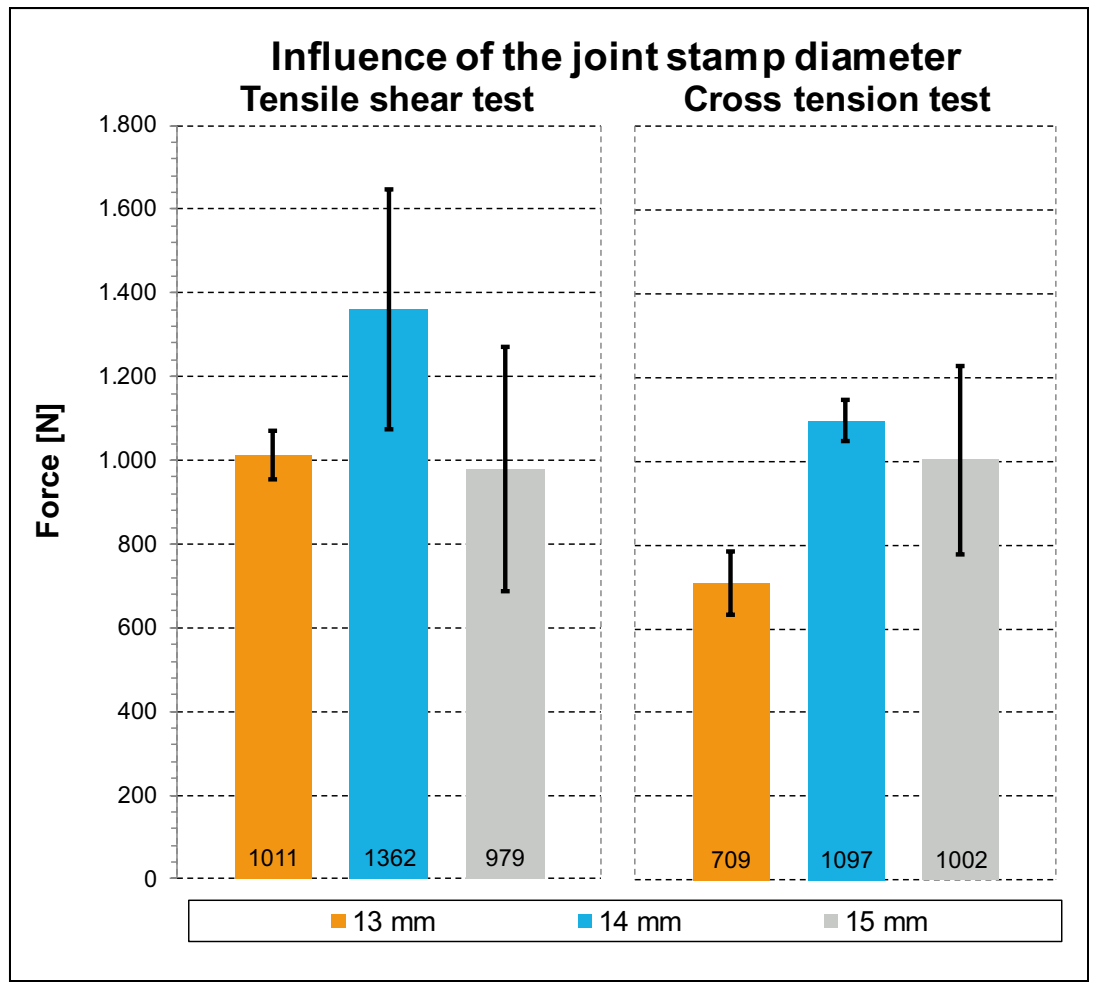

Fig. 10 Influence of the joint stamp diameter: mechanical properties

\subsection{Process description}

To form the thermoplastic composite, this must be plasticized locally (Fig. 4). Melting alone will not permit sufficient forming, however, since the continuous fiber fabric is held in position by the non-plasticized areas of the composite. For this reason, the composite must have a defined cut in the joint area so that the individual fiber rovings can be formed in such a way that a form-fit undercut is achieved between the thermoplastic composite and the metallic joining partner. The metallic joining partner is prepared with a through-hole, and the heated joining area of the composite material is penetrated through this hole by means of a descending punch, thus, forming a rivet head (Fig. 5).

Since the thermal formability of the thermoplastic composite is exploited, no higher forces are required to produce the joint by comparison to clinching pure metal sheets. The design of the joining equipment used is, thus, readily manageable and does not require a solid base frame. The necessary components were, thus, integrated into a hot-plate welding system familiar from plastics welding (Fig. 6). In this case, a high-speed system was chosen (Bielomatik K2150). The movement of the slides can be achieved at a speed of up to $800 \mathrm{~mm} / \mathrm{s}$. A maximum joining force of $500 \mathrm{~N}$ can be attained.
Fig. 11 Influence of the joint stamp diameter: micrographs

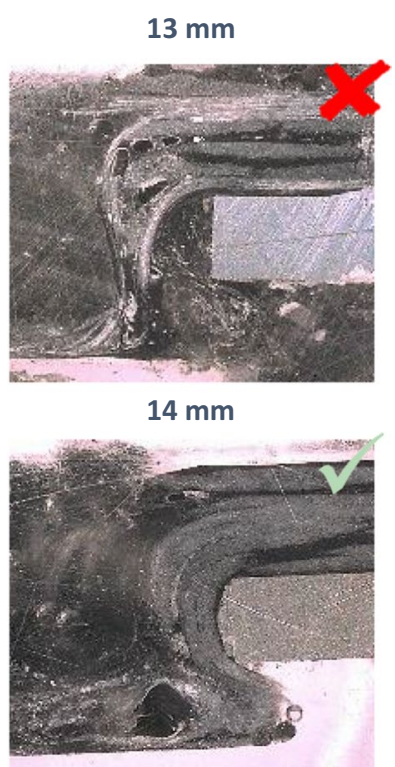

$15 \mathrm{~mm}$

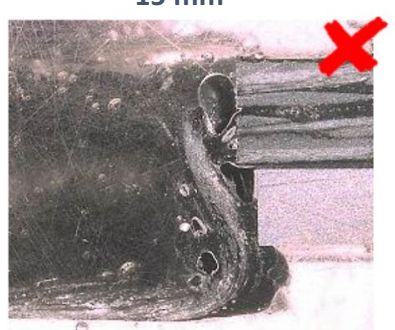




\begin{tabular}{|c|}
\hline $\begin{array}{c}\text { Joining Technology } \\
\text { Joint Stamp Riveting }\end{array}$ \\
Materials \\
Tepex dynalite 104RG-600 $(2 \mathrm{~mm})$ \\
EN AW-5754 $(1.5 \mathrm{~mm})$
\end{tabular}

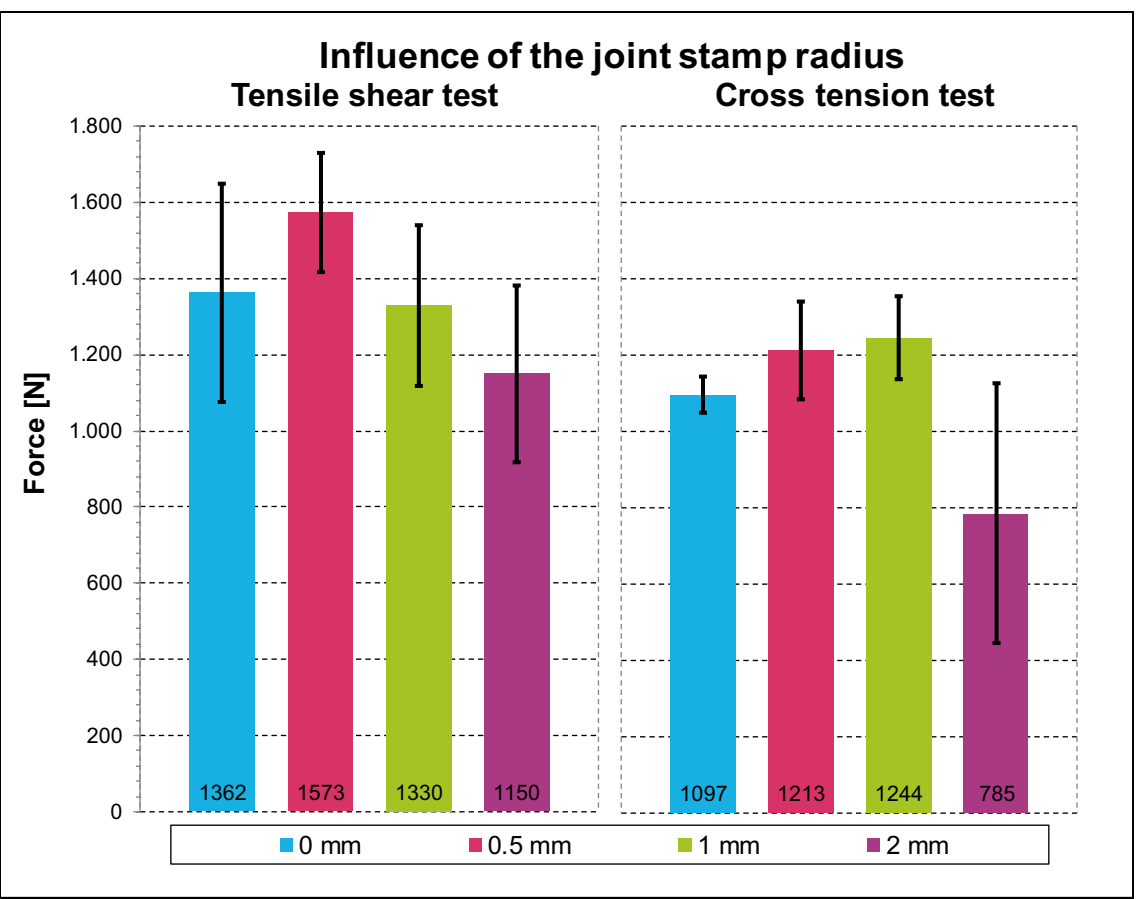

Fig. 12 Influence of the joint stamp radius: mechanical properties

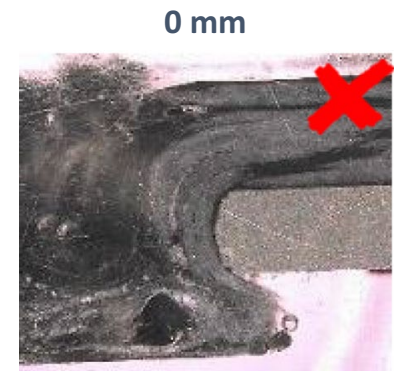

$0.5 \mathrm{~mm}$
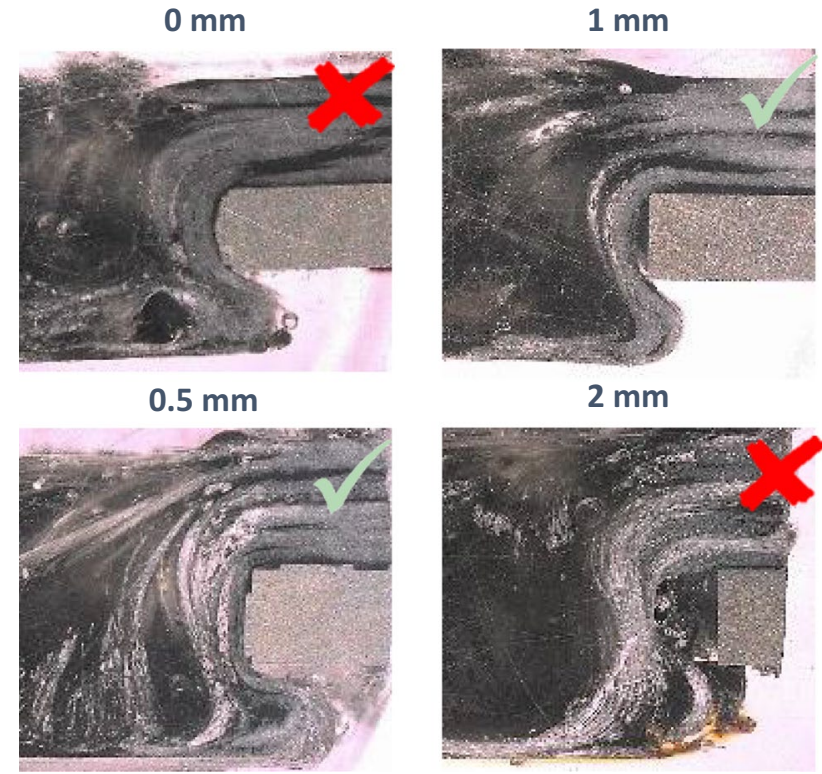

$2 \mathrm{~mm}$

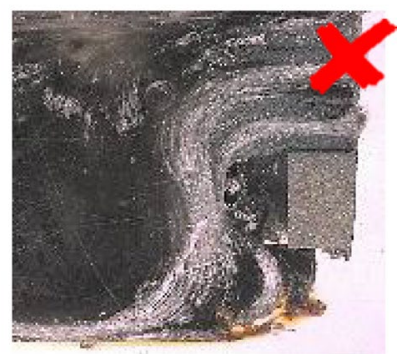

Fig. 13 Influence of the joint stamp radius: micrographs

\subsection{Joining system}

The system is divided into three sub-components which are fixed on horizontal slides. The joining part holder has the task of aligning and fixing the metal part and the FRP to each other and to the die. The components are held in place by hold-down devices. The holder additionally carries the necessary die with the corresponding rivet head geometry. Here, the thickness and diameter of the rivet head are relevant geometry parameters and were investigated (thickness $1-2 \mathrm{~mm}$, diameter $17-19 \mathrm{~mm}$ ). The die is heated at the rear by an integrated heating element which consists of two heating cartridges (Ihne + Tesch PDE 8D 60L $230 \mathrm{~V}$ $150 \mathrm{~W}$ ). Depending on the requirements, the fixture holds the testpiece geometries for an overlap tensile shear test or a cross-tension test.

An infrared radiator is used as the heating element, enabling spot heating of the thermoplastic composite (Krelus Pin-Heater 120/8, type S1-9.2-120, $120 \mathrm{~W}, 4$ V, 30 A). This is a metal foil emitter in the medium wave spectrum. The maximum intensity is $2.4 \mu \mathrm{m}$, which corresponds to a temperature of $850{ }^{\circ} \mathrm{C}$ in the metal foil. The advantage of such an IR emitter is its design freedom. A circular ring with an outer diameter of $16.3 \mathrm{~mm}$ and an inner diameter of $11.9 \mathrm{~mm}$ is used for joint stamp riveting. This allows the necessary selective heating to prevent the fibers of the FRP from slipping into the joint area during forming. The FRP can then just be heated in the area of the joint, while all the other areas remain relatively cold. In addition, no mask is required by the emitter, which heats up during the joining cycles and 


\begin{tabular}{|c|}
\hline Joining Technology \\
\hline Joint Stamp Riveting \\
\hline Materials \\
\hline Tepex dynalite 104RG-600 (2 mm) \\
\hline EN AW-5754 (1.5 mm) \\
\hline Sample Geometry \\
\hline following DIN EN ISO 14272/14273 \\
\hline Die Geometry \\
\hline $17 / 18 / 19 \mathrm{~mm} \times 2 \mathrm{~mm}$ \\
\hline Joint Stamp Geometry \\
\hline $14 \mathrm{~mm} \times 0.5 \mathrm{~mm}$ \\
\hline Temperature \\
\hline Die $50^{\circ} \mathrm{C}$, Joint Stamp $250^{\circ} \mathrm{C}$ \\
\hline Cut Geometry \\
\hline $15 \mathrm{~mm} \times 1.5 \mathrm{~mm} \times$ Cross $0^{\circ}$ \\
\hline Test \\
\hline Tensile shear test / Cross tension tes \\
\hline Test Boundary Conditions \\
\hline Zwick 1446, Load Cell 10 kN \\
\hline Test velocity $10 \mathrm{~mm} / \mathrm{min}$ \\
\hline
\end{tabular}

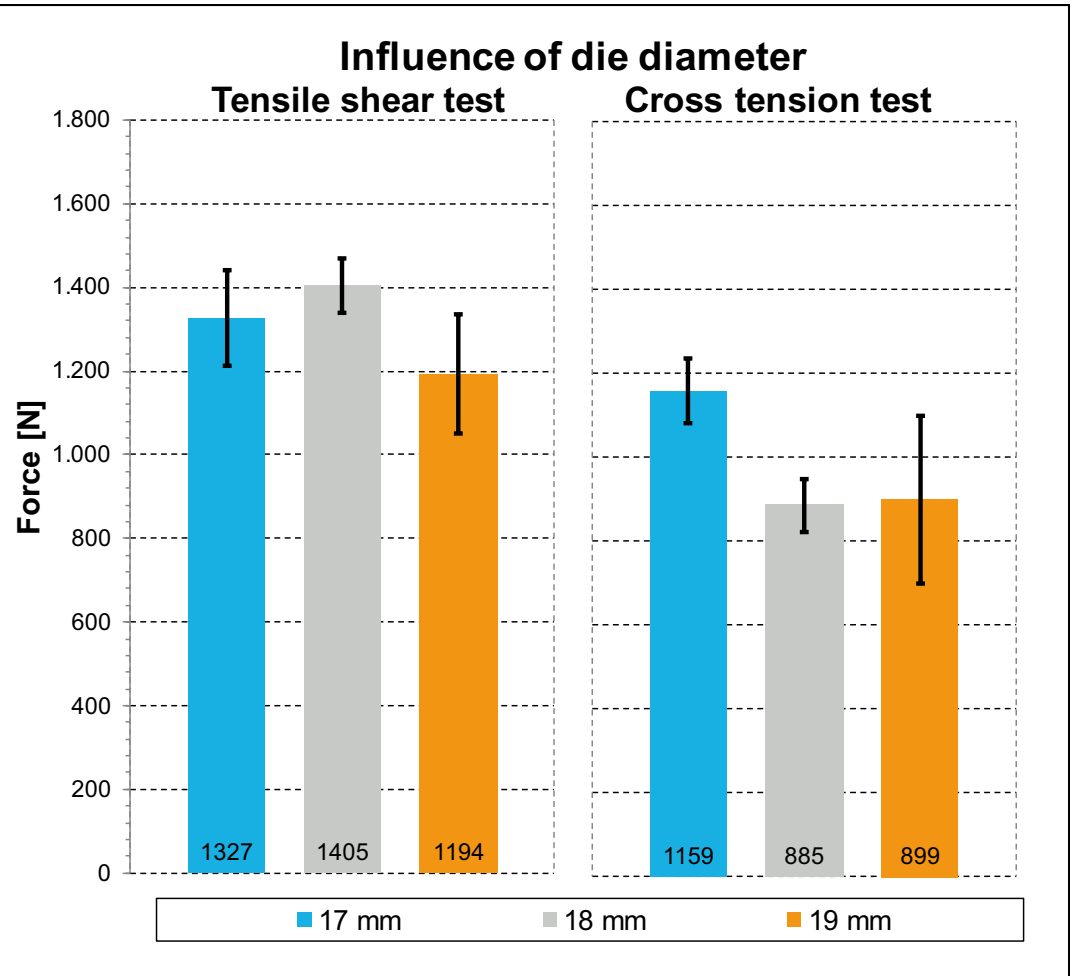

Fig. 14 Influence of the die geometry diameter: mechanical properties

influences the heating of the FRP. The metal part is not heated up directly, but absorbs the heat from the FRP and the heated die. For forming the TPC, heating to a temperature above the crystallite melting temperature is necessary (e.g., for PP $165{ }^{\circ} \mathrm{C}$ or for PA6 $226^{\circ} \mathrm{C}$ ). The temperature of the TPC was not actively measured in the process. Therefore, heating curves for the materials were determined to define a suitable process window.

The third slide carries the temperature-controlled joint stamp, which ensures the requisite forming stroke. Heating is provided by an integrated heating cartridge (Ihne + Tesch PDS 6,5D 60L $230 \mathrm{~V} 125 \mathrm{~W}$ ). The geometry parameters of the joint stamp are the diameter and the radius at the front edge. The joint stamp must be as centrally positioned to the die as possible in order to avoid misalignment. This is also familiar from elementary clinching.

The joining process starts with the insertion and fixing of the joining partners. The exact positioning is realized via cylindrical pins, as is familiar from punching technology, and the parts to be joined are fixed via the hold-down devices. The machine cycle can now be started. The IR emitter moves forward and heats the thermoplastic composite at a distance of approx. 5-7 $\mathrm{mm}$ depending on the matrix material and its thickness. After heating, the IR heater moves back and the joint stamp moves forward so that the joining process starts. Because of the high-speed hot-plate welding machine, the changeover time is around
$0.7-1 \mathrm{~s}$, which is quite good in relation to the cooling process of the infrared-heated thermoplastic composite. The stamp forms the melted area of the composite through the hole in the metal sheet, applying a joining force of about $500 \mathrm{~N}$ and a joining speed of $10 \mathrm{~mm} / \mathrm{s}$. A rivet head with an undercut is formed by the die, and the fibers of the composite geometrically claw on the edge of the hole in the metal sheet. After the composite has cooled down for $7 \mathrm{~s}$, the joined components are removed.

\section{Investigations, materials, and methods}

The initial investigations [36] with a first-generation joining system only considered one joint stamp and die geometry. The first results showed tensile shear forces in the range of $2 \mathrm{kN}$ and demonstrated a functional approach of this novel joining technology. A closer look at the structural properties of the joined joints showed that the full load capacity is not exhausted. Investigations with the computer tomograph were, thus, able to show how the deflection of the glass fibers progresses in the thermoplastic composite. Areas with complete deflection were detected, as were some areas where the deformation in the joint area damaged the glass fibers in the FRP used. This was attributable to the geometry of the joint stamp. The sharp edges meant that the glass fibers in 
Fig. 15 Influence of the die geometry diameter: micrographs
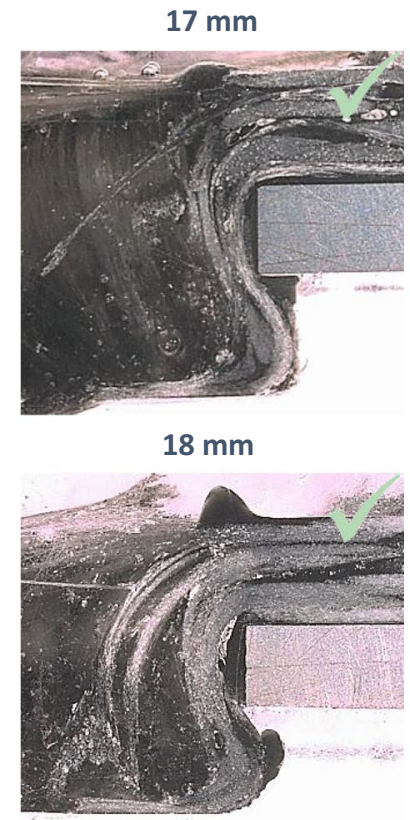

$19 \mathrm{~mm}$

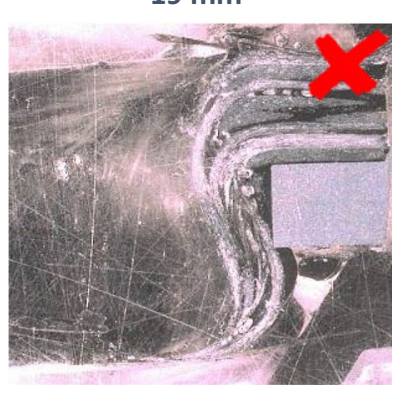

the FRP were partially sheared off instead of being formed. The joint stamp used had no radius at the front edge. Further investigations into the variation of the geometric parameters were then derived from this.

An investigation was, thus, carried out to improve the fiber deflection. The geometry of the die was also considered in this study, since, in addition to the fiber deflection, the deposition of the fibers is also decisive for the strength of the joint. Figure 7 shows the characteristic values that were investigated. For the joint stamp, these include the diameter and the radius at the leading edge. For the die, the values are the diameter and the depth. In addition, the cut geometry was analyzed as the preparation method for the thermoplastic composite in respect of fiber deflection. Here, the cutting parameters and the design were varied (Fig. 8). In order not to cause thermal damage to the polymer, moderate heating parameters were used for the investigations (distance to thermoplastic composite $7 \mathrm{~mm}$, output $105 \mathrm{~W}$, heating time $180 \mathrm{~s})$.
After the design optimization, relevant process parameters were studied in order to achieve the best fiber displacement into the rivet head, which was examined by means of CT. The performance of the mechanical properties is additionally shown in tensile shear tests and cross-tension tests for thermoplastic composites with polypropylene and polyamide in three different thicknesses (1, 2, $3 \mathrm{~mm})$.

In the investigations, the combination of a thermoplastic composite of type "Tepex dynalite 104-RG600" [37] and an aluminum sheet to EN AW-5754 was used. In the case of the composite, the type designation indicates a thickness of $2 \mathrm{~mm}$ or 4 layers of glass fiber fabric with twill $2 / 2$ weave. The matrix material is a polypropylene. In addition, a polyamide 6 type was added for extensive investigations (Tepex dynalite 102-RG600 [37]) and also a second aluminum (EN AW-5182). The choice of material was based on the production volume of different types of thermoplastic composites. This ensures that the selected composite is widely used and is the one with the most applications. The same procedure was followed for the aluminum sheet. The thickness here is $1.5 \mathrm{~mm}$.

The joining system has been developed in such a way that it can process two test specimen types for different load cases. An overlap tensile shear test specimen and a crosstension test specimen can, thus, be produced. The procedure is based on DIN EN ISO 14272 and 14273. The geometry is shown in Fig. 9.

In addition, it is necessary to prepare the parts to be joined. The aluminum sheet was provided with a circular hole with a diameter of $16 \mathrm{~mm}$ as part of the investigations. The hole was first produced by milling on a conventional milling machine. In the case of the thermoplastic composite, a cross-cut is also made in order to ensure the mobility of the fiber bundles during forming. The cross-cut was made in the fiber direction by milling. A CNC milling portal was used for this purpose (Charlyrobot charly4U type 6). The milling geometry was varied in the investigations. In the final investigations into the mechanical properties, the preparation methods were adapted to near-series production methods. Thus, the holes in the aluminum sheet were produced by punching, and the cuts in the thermoplastic composite were produced by waterjet cutting.

Microscopic methods were used for the examination of the joint. In this process, sections of the joining spots were taken and analyzed using a digital reflected-light microscope (Keyence VHX400) at $\times 30$ magnification. In addition, CT images were obtained for individual settings. A NanoCT system was used for this purpose (GE Measurement \& Control Solutions, phoenix nanotom s). To investigate the mechanical properties, a shear tensile test and a cross-tension test were performed. In the cross-tension test, additional restraint was used in accordance with DIN EN ISO 14272. The tests were carried out on a Zwick/Roell 1446 with a $10 \mathrm{kN}$ load 


\begin{tabular}{|c|}
\hline Joining Technology \\
\hline Joint Stamp Riveting \\
\hline Materials \\
\hline Tepex dynalite 104RG-600 (2 mm) \\
\hline EN AW-5754 (1.5 mm) \\
\hline Sample Geometry \\
\hline following DIN EN ISO 14272/14273 \\
\hline Die Geometry \\
\hline $17 \mathrm{~mm} \times 1 / 1.5 / 2 \mathrm{~mm}$ \\
\hline Joint Stamp Geometry \\
\hline $14 \mathrm{~mm} \times 0.5 \mathrm{~mm}$ \\
\hline Temperature \\
\hline Die $50{ }^{\circ} \mathrm{C}$, Joint Stamp $250^{\circ} \mathrm{C}$ \\
\hline Cut Geometry \\
\hline $15 \mathrm{~mm} \times 1,5 \mathrm{~mm} \times$ Cross $0^{\circ}$ \\
\hline Test \\
\hline Tensile shear test / Cross tension test \\
\hline Test Boundary Conditions \\
\hline Zwick 1446, Load Cell 10 kN \\
\hline Test velocity $10 \mathrm{~mm} / \mathrm{min}$ \\
\hline
\end{tabular}

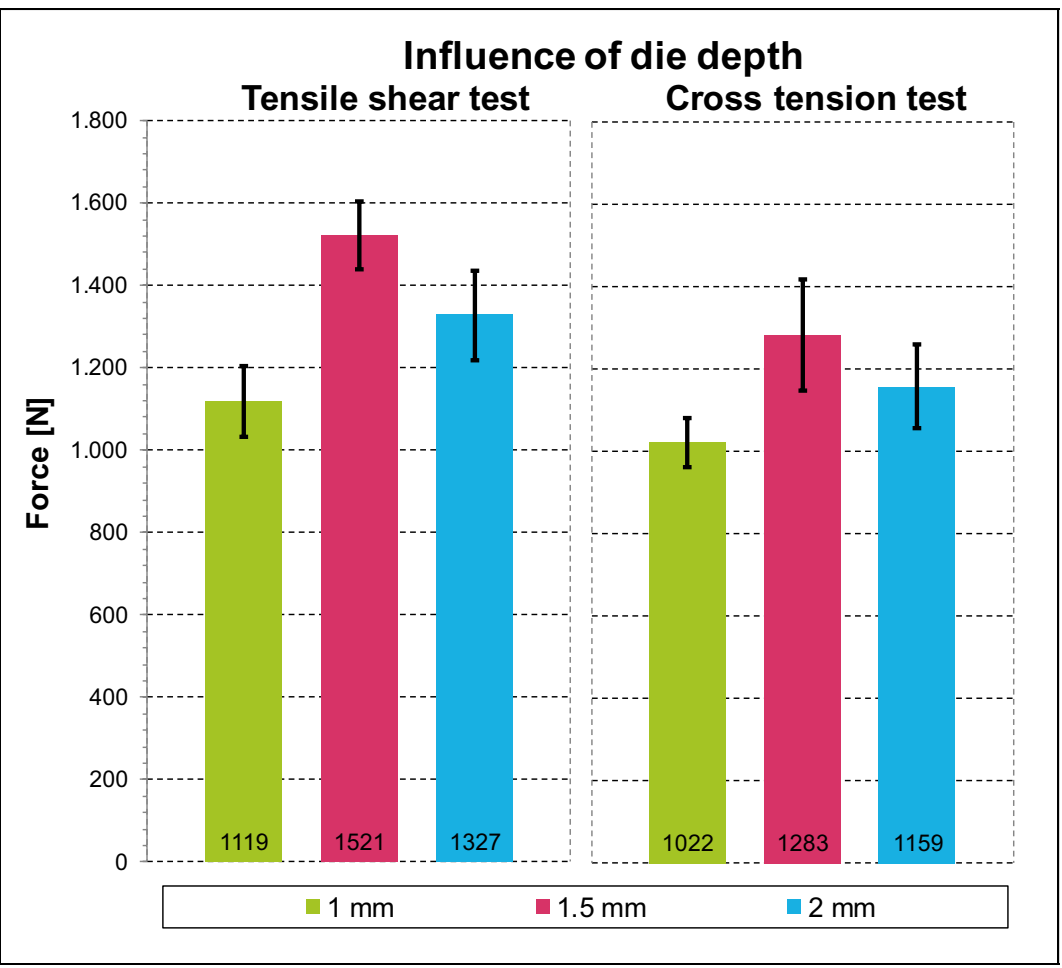

Fig. 16 Influence of the die geometry depth: mechanical properties

Fig. 17 Influence of the die geometry depth: micrographs

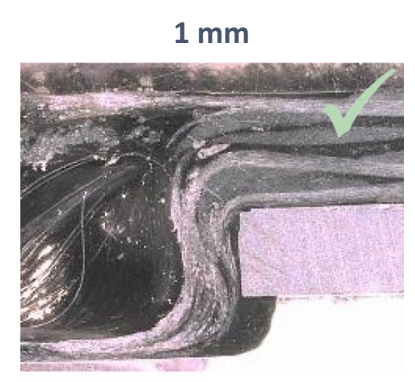

$1.5 \mathrm{~mm}$

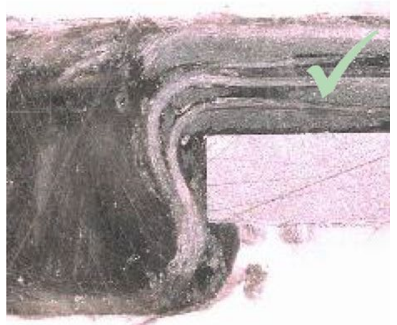

$2 \mathrm{~mm}$

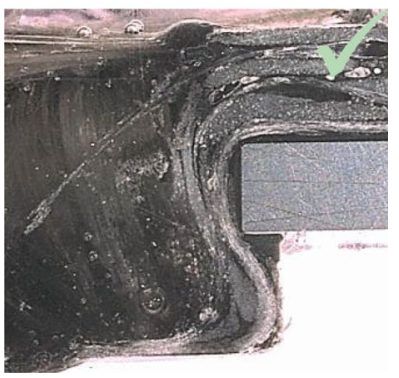

cell. A test speed of $10 \mathrm{~mm} / \mathrm{min}$ was set. The maximum force was determined for the evaluation.

\section{Results and discussion}

\subsection{Joint stamp geometry}

Figure 10 shows the results of the investigation of different joint stamp diameters with a constant die geometry. For a circular hole in the aluminum sheet of $16 \mathrm{~mm}$, the stamp diameters $13 \mathrm{~mm}, 14 \mathrm{~mm}$, and $15 \mathrm{~mm}$ were considered, without an edge radius. The results of the quasi-static mechanical tests for the tensile shear and cross-tension loads are shown in the diagram. Corresponding micrographs are shown in Fig. 11, with the largest diameter showing a similar picture to the initial tests. The fiber rovings are largely sheared off at the level of the aluminum sheet and can, therefore, only transmit small forces. This is confirmed by the mechanical tests, which have a high standard deviation. With the small diameter, little material is deformed, and hence, there is only moderate compression of the joint area, although the deflected fibers remain intact. The fiber rovings are only slightly deflected into the undercut. A compromise is achieved with the average diameter thickness of $14 \mathrm{~mm}$. Here, the tensile shear and cross-tension forces are at their 


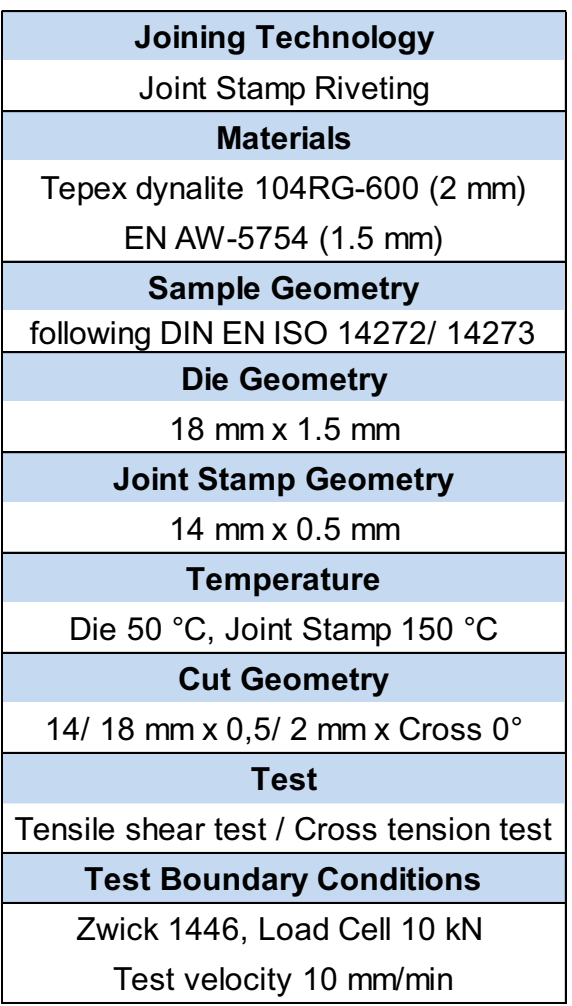

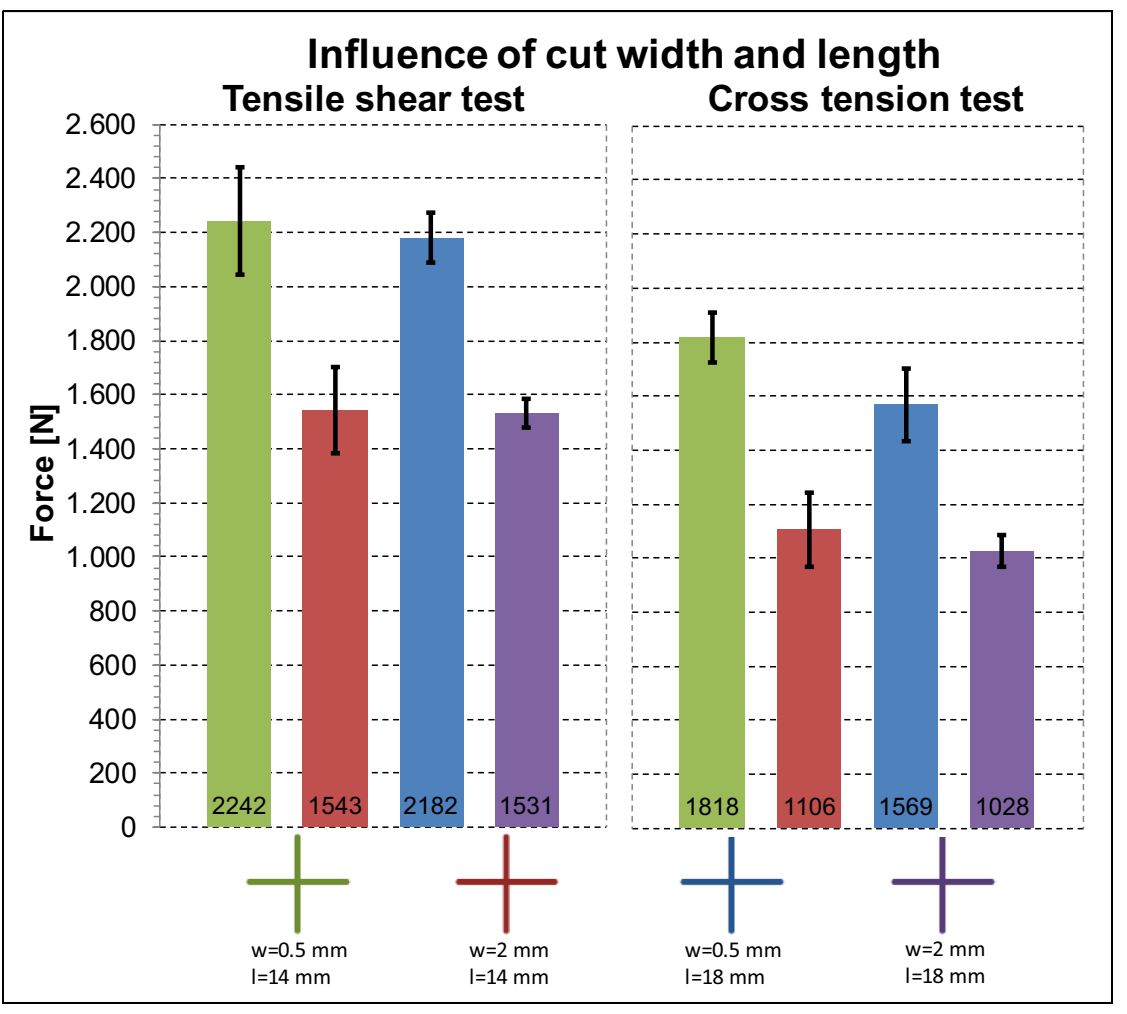

Fig. 18 Influence of the cutting width and length: mechanical properties

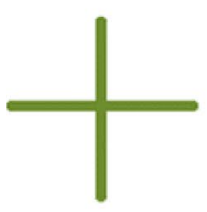

$w=0.5 \mathrm{~mm}$ I $=14 \mathrm{~mm}$
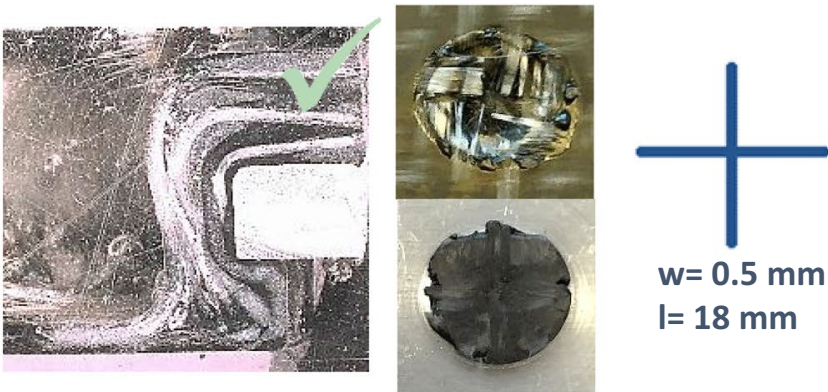

$\mathbf{w}=0.5 \mathrm{~mm}$

$\mathrm{I}=18 \mathrm{~mm}$
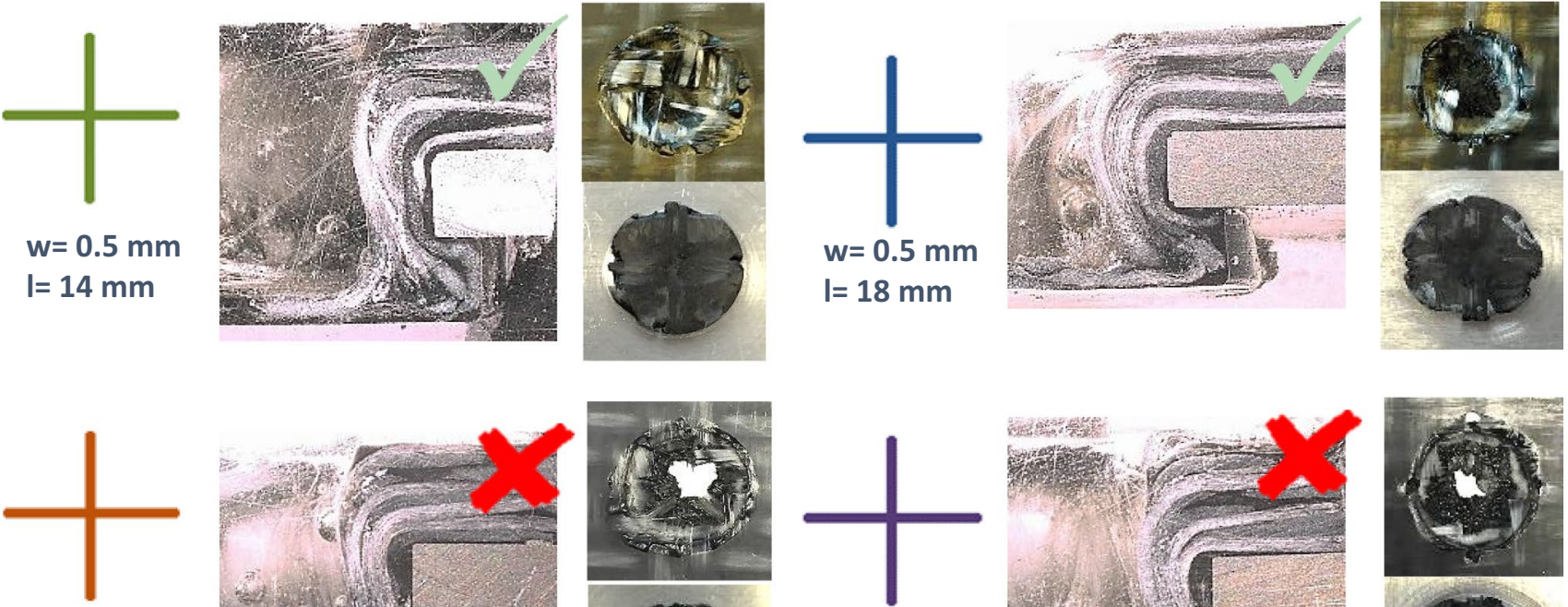

$\mathbf{w}=\mathbf{2} \mathrm{mm}$ I $=14 \mathrm{~mm}$
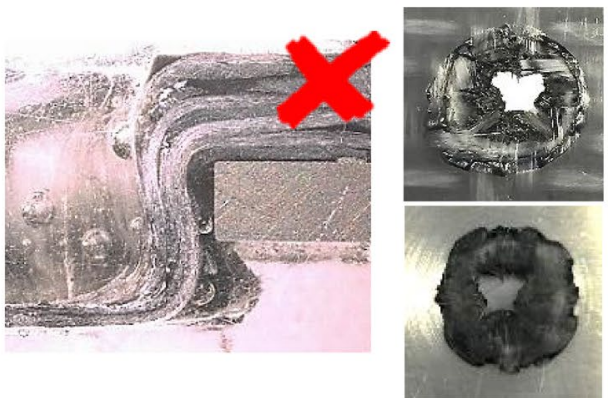

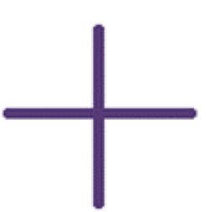

$\mathrm{w}=\mathbf{2} \mathrm{mm}$

$\mathrm{I}=18 \mathrm{~mm}$
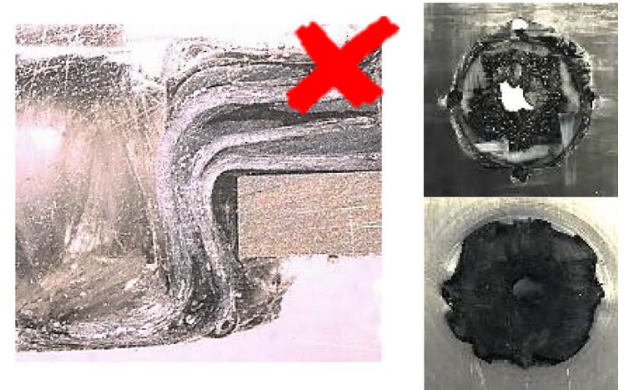

Fig. 19 Influence of the cutting width and length: micrographs 


\begin{tabular}{|c|}
\hline $\begin{array}{c}\text { Joining Technology } \\
\text { Joint Stamp Riveting }\end{array}$ \\
Materials \\
Tepex dynalite 104RG-600 $(2 \mathrm{~mm})$ \\
EN AW-5754 $(1.5 \mathrm{~mm})$
\end{tabular}

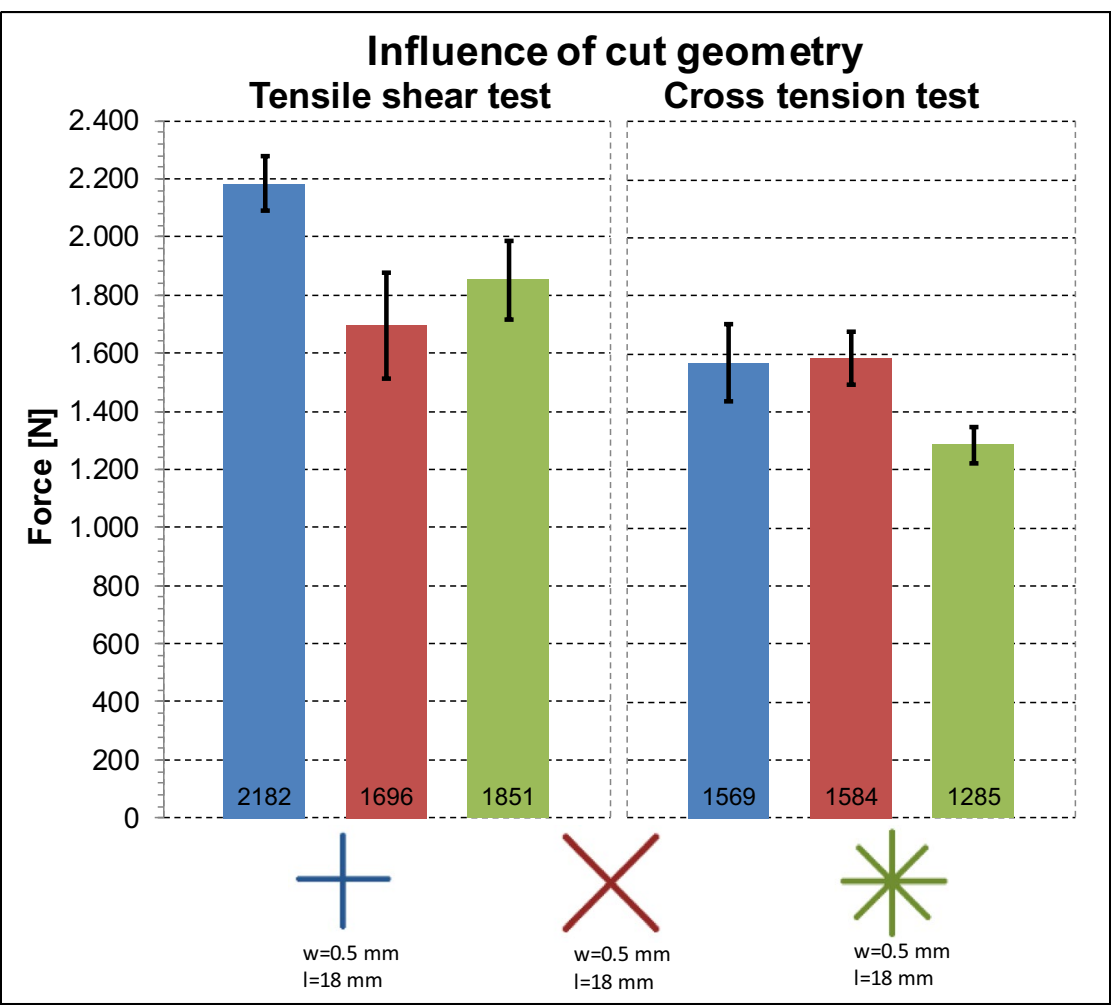

Fig. 20 Influence of the cutting geometry: mechanical properties

highest, although the rivet head is not well filled. Some fiber rovings are directed into the undercut, and the damage caused to the fibers by the joint stamp is only minor.

When looking at the edge radius (Figs. 12 and 13), it is apparent that a minimum radius of $0.5 \mathrm{~mm}$ is already sufficient to protect the fibers during forming and not to damage them. If the radius is increased further, the fibers can no longer be sufficiently embedded and are then unsorted, as is clear from the micrographs. The tensile shear and head tension tests confirm this on the basis of the force values achieved.

\subsection{Die geometry}

The analysis of the die geometry with regard to the diameter (Figs. 14 and 15) shows the importance of the rivet head shape. This becomes particularly clear in the crosstension test where the rivet head is only completely filled with the small diameter $(17 \mathrm{~mm})$ and, consequently, has an undercut which leads to higher forces. The material available for filling the rivet head is limited, since no additional material is used. The volume of the rivet head should, therefore, not be too large. The use of smaller diameters is, thus, recommended.

The influence of the rivet head shape also becomes clear when considering the variation in die depth
(Figs. 16 and 17). The available volume of the rivet head must not be too large if the tensile forces are to be high. At the same time, the deposition of fibers in the undercut of the rivet head is decisive. This applies above all for the cross-tension load and can be seen in the grain pattern and the tensile forces. For the shear tensile load, the depth of the fiber draw-in is more important, which means that, despite moderate rivet head characteristics, the tensile forces are higher at the greatest depth than at the lowest setting. The most favorable geometry, however, is the average depth $(1.5 \mathrm{~mm})$, which is evident for both types of load.

\subsection{Cuttings}

In order to achieve forming during joint stamp riveting without damaging the fibers of the thermoplastic composite, it is necessary to set a defined separation cut by way of preparation for the joining partner. This ensures the mobility of the fiber roving in the joint area, and the bundles can hook or anchor on the perforated edge of the metal sheet. This is precisely the difference compared with other methods, such as self-pierce riveting. The hooking produces the joint strength, whereas with self-pierce riveting, the thermoplastic composite quickly delaminates under load due to the fiber ends being butt-joined in front of a rivet element. The separation 


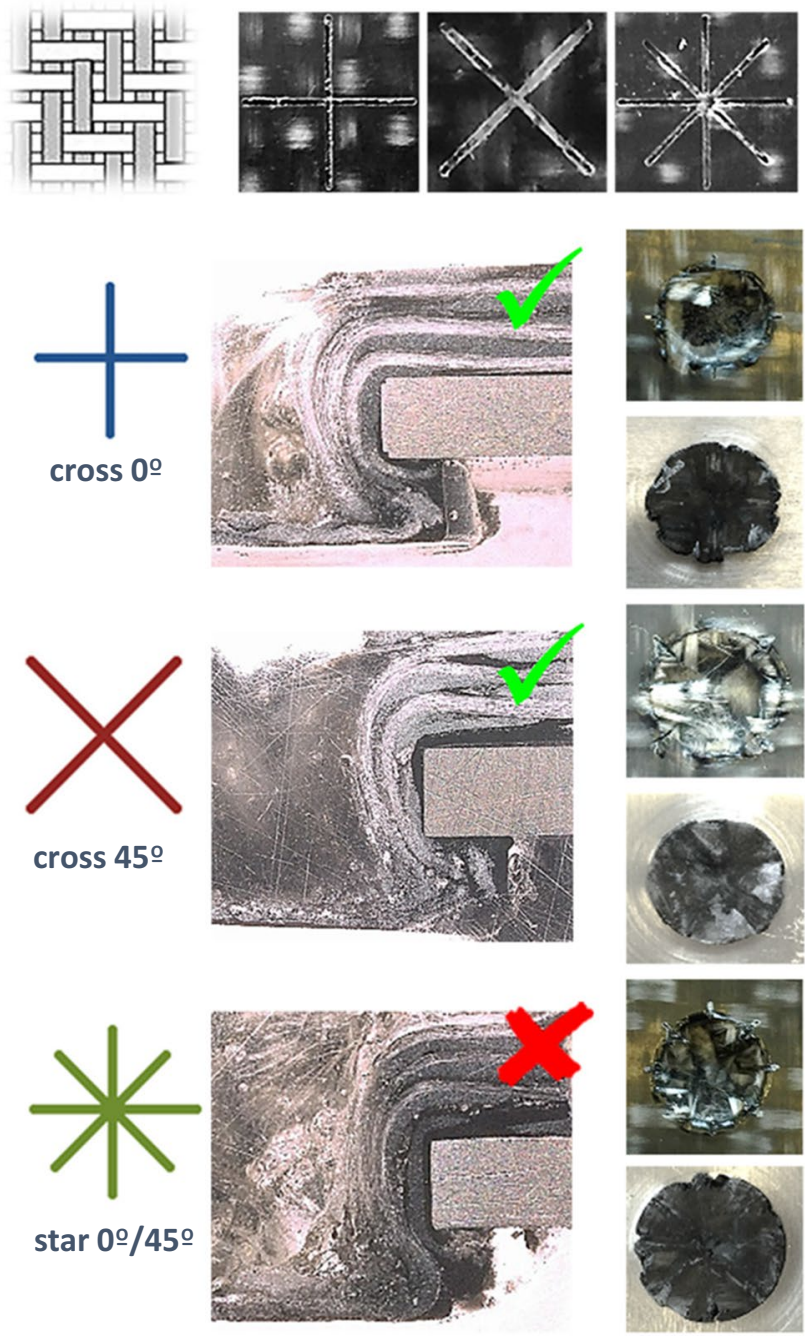

Fig. 21 Influence of the cutting geometry: micrographs

cut can be performed as an application during the cutting of the thermoplastic composite. Cutting is usually done by water jet cutting, which means the preparation step can be inserted at this point for a relatively small additional effort. For examination purposes, the cuts were made by milling on a mini-CNC system.

The cutting design (Fig. 9) can be freely selected. However, since the influence is unknown, the design was investigated. An initial tendency is to remove as little material as possible, as this is required for the rivet head and influences the characteristic and the mechanical properties. The three designs investigated vary in type, length, and width of the stroke. For a better understanding, Fig. 9 also shows the orientation of the fabric, so that a distinction is made between cross $0^{\circ}$, cross $45^{\circ}$, and star cutting.

The examination of the cutting length and width are shown exemplarily for cross $0^{\circ}$ cutting in Figs. 18 and 19. Both load types present very similar behavior with only a slight shift in the absolute force level here. The cutting width has a considerable influence on the strength of the joint, which can be explained by the small amount of material in the rivet head. The variants with wider cuttings show a clearly incomplete rivet head in each case, sometimes with a hole in the middle. In addition, the actual fiber roving length is slightly shorter. Together, these two factors result in a significantly lower joint strength. In the narrow cutting design, the rivet head is almost completely filled out. In addition, the micrographs show a better deflection of the fiber rovings into the rivet head. This leads to the joint strength of approx. $2.2 \mathrm{kN}$.

The cutting length reveals only few differences. The tensile shear load is about the same, with the difference becoming more obvious with the cross-tension load, which is about $250 \mathrm{~N}$. The hole diameter of the aluminum sheet used in this study is $16 \mathrm{~mm}$. This means that the cutting length here is $2 \mathrm{~mm}$ more or less in each case, with it at least being congruent with the joint stamp diameter. The recommendation at this point is, thus, to keep the cut rather small, and otherwise losses are to be expected in the area of the cross-tension
Fig. 22 CT images of the joining spot of a sample with cross Sect. $0^{\circ}$ (left) and $45^{\circ}$ (right)

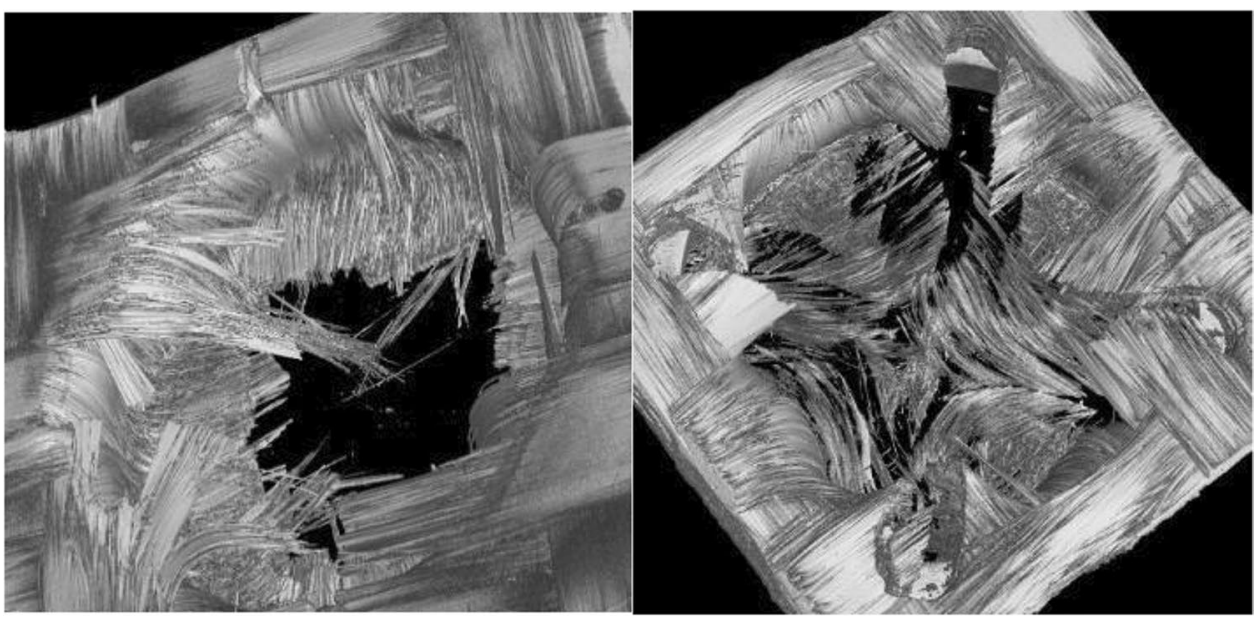




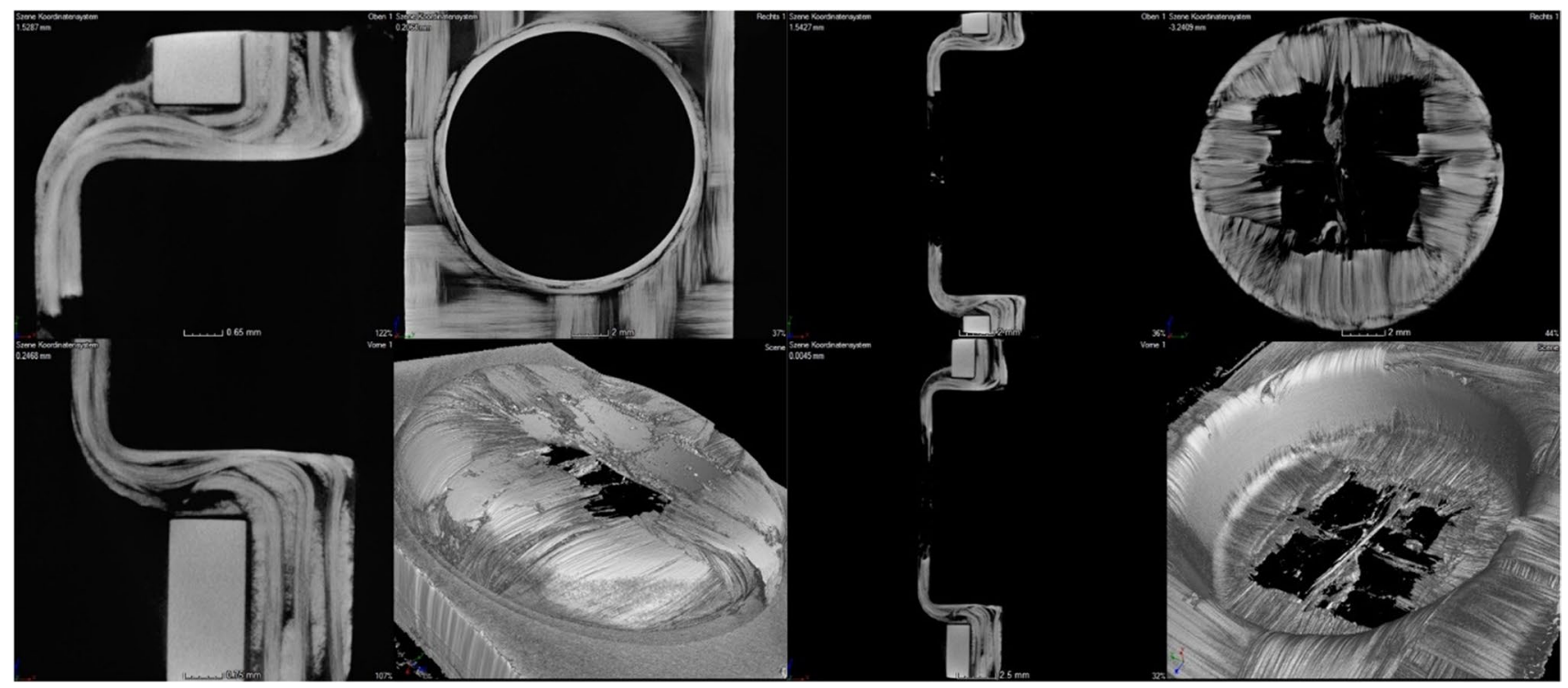

Fig. $23 \mathrm{CT}$ images of the joining spot after the structure and parameter analysis

\begin{tabular}{|c|}
\hline Joining Technology \\
Joint Stamp Riveting \\
Materials \\
Tepex dynalite 102/ 104RG-600 (1-3 mm) \\
EN AW-5182 (1-2 mm) \\
\hline Sample Geometry \\
following DIN EN ISO 14272/ 14273 \\
\hline Infrared Emitter \\
\hline $100-110$ W/ $80-180 \mathrm{~s} / 5 \mathrm{~mm}$ \\
\hline Joint Stamp + Die \\
\hline $13-15 \mathrm{~mm} \times 0.5 \mathrm{~mm}+17-18 \mathrm{~mm} \times 1-2 \mathrm{~mm}$ \\
\hline Temperature \\
\hline Joint Stamp $100-110^{\circ} \mathrm{C} /$ Die $70-100^{\circ} \mathrm{C}$ \\
\hline Joining Force \\
$500 \mathrm{~N}$ \\
\hline Cutting and Punching Geometry \\
\hline WC Cross $0^{\circ} 15 \times 1 \mathrm{~mm} /$ Punching $16 \mathrm{~mm}$ \\
\hline Test Boundary Conditions \\
\hline $\begin{array}{c}\text { Zwick } 1446, \text { Load Cell } 10 \mathrm{kN} \\
\text { Test velocity } 10 \mathrm{~mm} / \mathrm{min}\end{array}$ \\
\hline
\end{tabular}

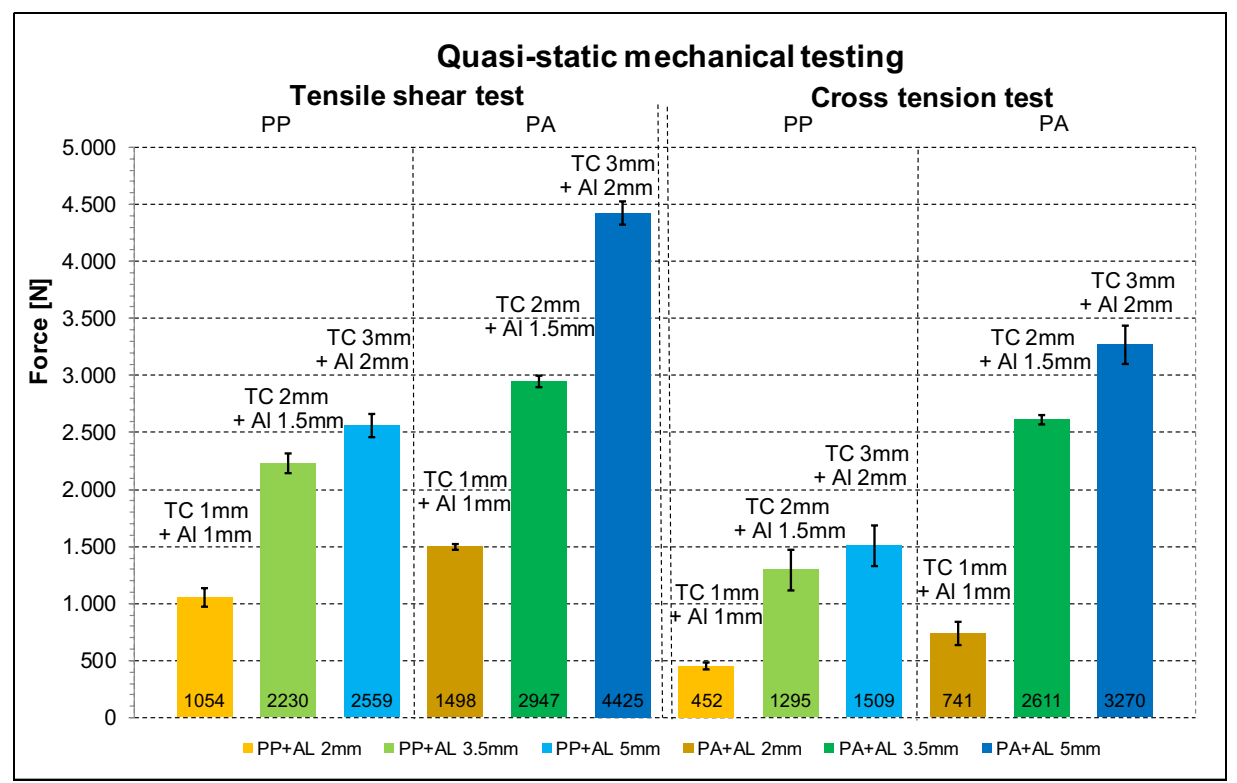

Fig. 24 Quasi-static mechanical testing: tensile shear test and cross-tension test

strength. The cut length should, therefore, be between the diameter of the sheet hole and the joint stamp, in this case between 14 and $16 \mathrm{~mm}$. In terms of the mechanical values, these two designs, therefore, come behind the cross $0^{\circ}$ and should not be given preference for this process.

When considering the cut design (Figs. 20 and 21), the cross with $0^{\circ}$ alignment to the fabric build-up shows the most favorable settings. This can be confirmed in both the tensile shear test and the cross-tension test. With this cut design, the fibers in the thermoplastic composite are cut lengthwise or orthogonally, which means that they are cut a maximum of once. The greatest length of the fiber rovings is, thus, achieved in the joint area. The cross $45^{\circ}$ and star cut designs partially cut the continuous fibers in two or more places. As a result, loose short fibers are present in the joint area and cannot participate in any entanglement with the drill hole in the metal plate. The loose fibers are shifted towards the center in the joint area and also affect the flow 
of the matrix material (Fig. 22). These two designs, thus, come behind the $0^{\circ}$ cross in terms of mechanical values and should not be given preference for the process.

\subsection{Mechanical properties}

After the analysis of the structure and the influencing factors, a parameter analysis was carried out. This provides information on the process control and crystallizes relevant control variables for the process. A process window was, thus, worked out, which is used in the further process. Together with the structural analysis, a status was obtained, which clearly shows the performance of the process. The mechanical parameters for the process, were, therefore determined. It proved possible to design the forming in the joining area in such a way that almost $100 \%$ of the fibers in the thermoplastic composite are formed in the rivet head area (Fig. 23). This highly favorable condition is shown in the CT image and is suitable for determining mechanical values. The investigations were divided into quasi-static tensile tests with the load types of an overlap tensile shear test and a cross-tension test.

Figure 24 shows the result of the investigations with the quasi-static tensile tests. FRP of the "Tepex" type with a polypropylene and a polyamide matrix was tested. The thickness combinations of $2 \mathrm{~mm}, 3.5 \mathrm{~mm}$, and $5 \mathrm{~mm}$ were considered. As the thickness increases, the maximum force increases. It is not, however, possible to determine any proportionality of the increase here. The thin joining part combination shows significantly lower values, which is mainly due to the small amount of material in the thermoplastic composite that is available for forming the rivet head. When the load direction changes from shear to cross-tension, the maximum force decreases accordingly. Here the values are consistently much lower. As expected, when comparing the materials with each other, the PA FRP shows higher values, which goes hand in hand with the familiar higher mechanical values of pure polyamide compared to pure polypropylene.

\section{Conclusion}

The novel joining technique of joint stamp riveting exploits the thermal formability of thermoplastic composites in order to form a joint. Through skillful preparation of the joining partners, it is possible to achieve damagefree fiber deflection of the glass fibers in the FRP. No additional joining elements are required with this process. In addition, high characteristic values are determined during the mechanical tests. The force flow is transmitted through the formed plastic material. High characteristic values can be achieved, similar to those obtained with widely used joining processes familiar from the literature, research, and industry. Finally, the project results successfully demonstrate the potential that the joining technology holds for hybrid joints of sheet metal and thermoplastic composites.

Acknowledgements IGF Project 18.586 N/DVS No. 11.053 of the Research Association for Welding and Allied Processes (DVS) was supported by the German Federation of Industrial Research Associations (AiF) under the program for promotion of industrial research (IGF) by the Federal Ministry for Economic Affairs and Energy (BMWi) based on a decision of the German Bundestag.

Funding Open Access funding enabled and organized by Projekt DEAL.

Open Access This article is licensed under a Creative Commons Attribution 4.0 International License, which permits use, sharing, adaptation, distribution and reproduction in any medium or format, as long as you give appropriate credit to the original author(s) and the source, provide a link to the Creative Commons licence, and indicate if changes were made. The images or other third party material in this article are included in the article's Creative Commons licence, unless indicated otherwise in a credit line to the material. If material is not included in the article's Creative Commons licence and your intended use is not permitted by statutory regulation or exceeds the permitted use, you will need to obtain permission directly from the copyright holder. To view a copy of this licence, visit http://creativecommons.org/licenses/by/4.0/.

\section{References}

1. Buedgam S, Freitag V, Hahn O, Ruther M (2004) Optimization of joining techniques for multi-material constructions in body making. ATZ Worldw 106:1132-1141

2. Rumpelt T (2017) Das Maximale rausgekitzelt. Automobil Industrie, Vogel

3. Seidlitz H, Kroll L, Ulke-Winter L (2011) Heavy-duty lightweight structures: force flux-maintaining spot connections. Kunstst Int 2011 (3):25-28

4. Ehrenstein GW (2007) Mit Kunststoffen konstruieren. Carl Hanser, Munich

5. Federation of Reinforced Plastics Industry (AVK) (2014) Handbuch Faserverbundkunststoffe/Composites. Springer Vieweg, Wiesbaden

6. Neitzel M, Mitschang P, Breuer U (2014) Handbuch Verbundwerkstoffe. Carl Hanser, Munich

7. Schuermann H (2007) Konstruieren mit Faser-Kunststoff-Verbunden. Springer, Berlin/ Heidelberg

8. Henning F, Moeller E (2011) Handbuch Leichtbau - Methoden, Werkstoffe, Fertigung, Carl Hanser, Munich/ Vienna

9. Throne J, Beine J (1999) Thermoformen: Werkstoffe, Verfahren, Anwendung. Carl Hanser, Munich

10. Lahr R (2007) Partielles Thermoformen endlosfaserverstärkter Thermoplaste. Dissertation, Kaiserslautern Technical University

11. Ickert L, Eckstein L, Thomas D, Tröster T (2012) Beitrag zum Fortschritt im Automobilleichtbau durch belastungsgerechte Gestaltung und innovative Lösungen für lokale Verstärkungen von Fahrzeugstrukturen in Mischbauweise. Research Association for Automotive Engineering (FAT), Berlin

12. Michaeli W, Preller F, Lambrecht L, Fischer K (2008) CAE für FVK - Von der Auslegung bis zur Anwendung. IKV-Colloquium, Aachen 
13. Breuer P (1997) Beitrag zur Umformtechnik gewebeverstärkter Thermoplaste. Dissertation, Kaiserslautern Technical University

14. Berthold U (2001) Beitrag zur Thermoformung gewebeverstärkter Thermoplaste mittels elastischer Stempel. Dissertation, Chemnitz Technical University

15. Friedrich HE, Meschut G (2003) Zukünftige Werkstoffe und Fügekonzepte im Automobilbau. In: Gemeinsame Forschung in der Klebtechnik (3. Colloquium), Duesseldorf

16. Hahn O, Timmermann R (2002) Wärmearme Fügetechniken für den Einsatz in Mischbauweisen. In: Dünnblechverarbeitung (SLV-Tagung), Munich

17. Wilhelm M, Fuessel U, Nancke T, Duschl M (2013) Herausforderung CFK-Stahl-Mischbau - Quantifizierung von Delamination infolge des umformtechnischen Fügens. In: DGZfP-Jahrestagung 2013, Dresden

18. Landgrebe D, Jaeckel M, Niegsch $R$ (2015) Influence of process induced damages on joint strength when self-pierce riveting carbon fiber reinforced plastics with aluminum. Key Eng Mater 651-653:1493-1498. https://doi.org/10.4028/www.scientific. net/KEM.651-653.1493

19. Wagner J, Wilhelm M, Baier H, Fuessel U, Richter T (2014) Experimental analysis of damage propagation in riveted CFRPsteel structures by thermal loads. Int J Adv Manuf Technol 75:1103-1113. https://doi.org/10.1007/s00170-014-6197-5

20. Honkanen M, Hoikkanen M, Vippola M, Vuorinen J, Lepistö $\mathrm{T}$ (2009) Metal-plastic adhesion in injection-molded hybrids. J Adhes Sci Technol 23(13-14):1747-1761. https://doi.org/10. 1163/016942409X12489445844435

21. Vittinghoff J, Drummer D (2014) Investigating the full-faced joining of polymer-metal hybrid structures. Conference Paper, ANTEC

22. Grujicic M, Sellappan V, Omar MA, Seyr N, Obieglo A, Erdmann M, Holzleitner J (2008) An overview of the polymerto-metal direct-adhesion hybrid technologies for load-bearing automotive components. J Mater Process Technol 197(13):363-373 (Elsevier). https://doi.org/10.1016/j.jmatprotec. 2007.06.058

23. Graham DP, Rezai A, Baker D, Smith PA, Watts JF (2014) The development and scalability of a high strength, damage tolerant, hybrid joining scheme for composite-metal structures. Compos A 64:11-24 (Elsevier). https://doi.org/10.1016/j.compositesa.2014. 04.018

24. Kashaev N, Ventzke V, Riekehr S, Dorn F, Horstmann M (2015) Assessment of alternative joining techniques for Ti-6Al-4V/ CFRP hybrid joints regarding tensile and fatigue strength. Mater Des 81:73-81 (Elsevier). https://doi.org/10.1016/j.matdes.2015. 04.051
25. Moroni F, Pirondi A, Kleiner F (2010) Experimental analysis and comparison of the strength of simple and hybrid structural joints. Int J Adhes Adhes 30:367 (Elsevier). https://doi.org/10.1016/j. ijadhadh.2010.01.005

26. Abibe AB, Amancio-Filho ST, Dos Santos JF, Hage E Jr (2011) Development and analysis of a new joining method for polymermetal hybrid structures. J Thermoplast Compos Mater 24:233 (Sage Publishers). https://doi.org/10.1177/0892705710381469

27. Kroll L, Seidlitz H (2014) High-strength mixed constructions with thermoplastic fibre composites and metals. Join Plast 2(2014):106-111

28. Podlesak F (2017) Entwicklung und Verifizierung eines vorlochfreien mechanischen Fügeverfahrens zum Verbinden von Leichtmetallen und Faser-Kunststoff-Verbunden. Dissertation, Chemnitz Technical University

29. Nagel P, Meschut G (2017) Flow drill screwing of fibre-reinforced plastic-metal composites without a pilot hole. Weld World 61:1057-1067. https://doi.org/10.1007/s40194-017-0493-2

30. Gude M, Hufenbach W, Kupfer R, Freund A, Vogel C (2015) Development of novel form-locked joints for textile reinforced thermoplastics and metallic components. J Mater Process Technol 216:140-145. https://doi.org/10.1016/j.jmatprotec.2014.09.007

31. Reisgen U, Schiebahn A, Schönberger J (2014) Innovative Fügeverfahren für hybride Verbunde aus Metall und Kunststoff. Lightweight Des 7(3):12-17

32. Spancken D, van der Straeten K, Beck J, Stötzer N (2018) Laserstrukturierung von Metalloberflächen für Hybridverbindungen. Lightweight Des 11(4):16-23

33. Schricker K, Alhomsi M, Bergmann JP (2020) Thermal efficiency in laser-assisted joining of polymer-metal composites. Materials 13:4875. https://doi.org/10.3390/ma13214875

34. van der Straeten K, Burkhardt I, Olowinsky A, Gillner A (2016) Laser-induced self-organizing microstructures on steel for joining with polymers. Phys Procedia 83:1137-1144. https://doi.org/10. 1016/j.phpro.2016.08.119 (Elsevier)

35. Seidlitz H, Fritzsche S, Ambrosio M, Kloshek A (2017) Advanced welding technology for highly stressable multi-material designs with fiber-reinforced plastics and metals. Open J Compos Mater 7:166-177. https://doi.org/10.4236/ojcm.2017.73010

36. Budde C (2017) Evaluierung neuer Fügetechniken für Organoblech-Hybridverbindungen. Dissertation, Paderborn University

37. Bond-Laminates (2020) Tepex ${ }^{\circledR}$ product families. https://bondlaminates.com/materials/tepexr-product-families/

Publisher's note Springer Nature remains neutral with regard to jurisdictional claims in published maps and institutional affiliations. 